\title{
Concepções de Educadoras de Berçário sobre Desenvolvimento Infantil e Interação Educadora-Bebê
}

\author{
Berenice Stéinmetz Klein \\ Programa de Pós-Graduação em Avaliação Psicológica das Faculdades Integradas \\ de Taquara, Taquara, RS, Brasil \\ Gabriela Dal Forno Martins ${ }^{1}$ \\ Programa de Pós-graduação em Educação da Pontifícia Universidade Católica \\ do Rio Grande do Sul, Porto Alegre, RS, Brasil
}

\begin{abstract}
Resumo
O presente estudo teve como objetivo caracterizar as concepções de educadoras de berçário a respeito do desenvolvimento infantil e da interação educadora-bebê. Participaram seis educadoras, que atuavam em escolas da rede municipal e atendiam bebês de quatro a dezesseis meses. As educadoras responderam a duas entrevistas semiestruturadas, cujas respostas foram avaliadas qualitativamente, através da analise de conteúdo. Os resultados indicaram que embora as educadoras tenham destacado importantes necessidades do bebê e aspectos relevantes que influenciam seu desenvolvimento, tenderam a descrevê-lo como pouco ativo e competente, menosprezando, por exemplo, suas competências para estabelecer trocas e compartilhamento de emoções com outros bebês e adultos, bem como para explorações através de movimentos livres. Além disso, ressaltaram a estimulação constante como prática principal da educadora na interação com o bebê. De forma geral, o estudo aponta para a relevância da formação continuada como estratégia para construir novas compreensões sobre o bebê e ampliar o escopo de ações da educadora de berçário para além das já consolidadas.
\end{abstract}

Palavras-chave: Concepções, educadoras, desenvolvimento infantil, interação, educação infantil.

\section{Educators' Conceptions about Child Development and Educator-Baby Interaction}

\begin{abstract}
This study aimed to characterize educators' conceptions about child development and educator-baby interaction. Participants included six female educators, who have worked in public schools and attended babies from four to sixteen months. Educators answered two semi structured interviews and their answers were qualitatively evaluated through a content analysis. The results indicated that although the educators have highlighted important baby's needs and relevant aspects that influence his development, they tended to describe him as little active and competent, belittling, for example, his potential to establish exchanges and sharing emotions with other babies and adults, as well as for exploration through free movement. In addition, they stressed the constant stimulation as the main educator practice in interaction with the baby. In general, the study points to the importance of continuing education as a strategy to build new understandings about the baby and broaden the scope of educator's actions beyond those already consolidated.
\end{abstract}

Keywords: Conceptions, caregivers, child development, interaction, childhood education.

Endereço para correspondência da: Rua Maestro Mendanha, 91/404, Porto Alegre, RS, Brasil 90620-130. Fone: (051) 93019356. E-mail: gdalfornomartins@gmail.com 


\section{Concepciones de Educadoras de Guarderías sobre el Desarrollo Infantil y la Interacción Educadora-Bebé}

\section{Resumen}

Este estudio tuvo como objetivo caracterizar las concepciones de educadoras de guarderías sobre el desarrollo infantil y la interacción educadora-bebé. Los participantes fueron seis educadoras, que trabajaban en las escuelas municipales, con bebés de cuatro a dieciséis meses. Las educadoras respondieron dos entrevistas semiestructuradas y las respuestas se evaluaron cualitativamente mediante una análisis de contenido. Los resultados indicaron que aunque los maestros han puesto de relieve las necesidades importantes del bebé y los aspectos relevantes que influyen en su desarrollo, tendió a describirlo como poco activa y competente, menospreciando, por ejemplo, sus poderes para establecer intercambios y compartir emociones con otros bebés y los adultos, así como para la exploración a través de libre movimiento. Además, destacaron la estimulación constante como práctica principal del educador en la interacción con el bebé. En general, el estudio apunta a la importancia de educación continuada como estrategia para construir una nueva comprensión sobre el bebé y ampliar el alcance de las acciones de la educadora más allá de los ya consolidados.

Palabras clave: Concepciones, educadoras, desarrollo infantil, interacción, educación infantil.

Um dos ambientes que cada vez mais tem feito parte da vida da criança, desde muito cedo, diz respeito à escola de Educação Infantil2. No Brasil, dados dos censos escolares dos últimos três anos (2013 a 2015) revelaram um aumento de 4,5\% de crianças matriculadas na Educação Infantil em geral e um aumento de $12 \%$ de crianças matriculadas em creches (Instituto Nacional de Estudos e Pesquisas Educacionais Anísio Teixeira [Inep], 2013, 2015). Além disso, em 2014, o governo estabeleceu a meta de que até o final de 2016 todas as crianças de quatro a cinco anos devem estar, obrigatoriamente, matriculadas na pré-escola e de que, até 2020, as creches devem atender $50 \%$ das crianças de até três anos (Ministério da Educação [MEC], 2014).

Em função disso, verifica-se uma crescente preocupação da sociedade em geral e da comunidade científica em compreender o papel desse contexto no desenvolvimento da criança. Por exemplo, Lordelo, Chalhub, Guirra e Carvalho (2007), ao realizarem uma revisão de estudos sobre essa temática, concluíram que grande par-

Escola de Educação Infantil (0 a 5 anos e 11 meses), que compreende a creche (0 a 3 anos) que se divide em berçário ( 0 a 2 anos) e maternal (2 a 3 anos) - e pré-escola (4 e 5 anos e 11 meses). te dos resultados desenvolvimentais verificados nas crianças que frequentam escolas de Educação Infantil estão relacionados aos comportamentos das educadoras.

Caracterizar tais comportamentos e avaliar sua adequação, no entanto, não é tarefa fácil. Isso porque não existe uma forma única e padronizada de interagir com as crianças e promover seu desenvolvimento. Por isso, para compreender os comportamentos específicos de um adulto em relação à criança é relevante levar em consideração as crenças que os embasam e lhes dão significado (Carvalho, Pedrosa, \& Rossetti-Ferreira, 2012; Vartuli, 2005). Entende-se que as crenças refletem um conjunto de ideias, que podem incluir conhecimentos, expectativas, valores, impressões ou concepções. Segundo Harkness e Super (1996), as mesmas estão implícitas nas atividades diárias, escolhas e decisões que tomamos, de modo que, ao conhecer as crenças de um adulto, é possível entender melhor o contexto de vida da criança.

Este estudo, ao focalizar a temática das concepções das educadoras sobre o desenvolvimento infantil e a interação educadora-bebê, toma como ponto de partida a perspectiva sociointeracionista do desenvolvimento humano, a qual, conforme Felipe (2001), pressupõe que a capa- 
cidade de aprender e conhecer ocorre através da interação do sujeito com o meio no qual ele vive e da mediação dessa comunidade. Nesse sentido, embora as crianças nasçam com potencialidades típicas da espécie humana, é na interação com o mundo que os adultos organizam e através das trocas que fazem com ele que tais potencialidades são efetivamente desenvolvidas (Carvalho et al., 2012).

Portanto, Piaget (1936/1978), Vygotsky (1984) e Wallon (1941/1995), principais representantes de tal perspectiva, entendem esse processo como dinâmico, pois as crianças desenvolvem-se através do conhecimento do próprio corpo, dos objetos a sua volta e da interação que fazem com as outras crianças e os adultos de seu convívio social. As abordagens desses autores descrevem as crianças como seres ativos, que buscam essa troca para desenvolver sua capacidade afetiva, a sensibilidade, a autoestima, o raciocínio, o pensamento e a linguagem (Felipe, 2001).

De forma resumida, é possível afirmar que, para os três teóricos, a criança nasce com potencialidades, mas os resultados desenvolvimentais vão depender de como tais potencialidades interagem com o meio no qual a criança vive. No início da vida, esse meio é determinado, em grande parte, pelas interações que a criança estabelece com os adultos, daí a importância de compreender a natureza dessas interações.

No que diz respeito ao conceito de interação, tem-se destacado na literatura as contribuições de Donald Woods Winnicott e John Bowlby. Winnicott (1964/1985), apesar de psicanalista, defende que o ambiente tem grande influência no desenvolvimento e aprendizado da criança, mais do que o inconsciente. Para ele, cada ser humano possui um potencial inato para amadurecer e se integrar, mas para que haja um desenvolvimento emocional saudável, o ser humano necessita de um ambiente facilitador, que inclua cuidados adequados, os quais, no início da vida, estão principalmente associados ao holding (segurar/sustentar). Esse termo é utilizado por ele para descrever o fato de o cuidador tornar o ambiente seguro, proteger o bebê, sustentá-lo, saber o que o bebê está necessitando e responder a essas necessidades.
Assim como Winnicott, John Bowlby estudou a importância das primeiras relações para o desenvolvimento, enfatizando, da mesma forma, a importância das mesmas na vida dos bebês (Bowlby, 1969/2002). Ao falar do conceito de interação, Bowlby recorre ao fenômeno do apego, enquanto Winnicott usa o termo que chamou de vínculo primário (Cavalcanti, 2007). Ao utilizarem esses dois conceitos, ambos referem-se a uma relação bidirecional, na qual, segundo Cavalcanti (2007), não apenas o comportamento do bebê é moldado pelo comportamento da mãe, mas também o comportamento da mãe é moldado pelo comportamento do bebê. Isso porque os bebês apresentam uma capacidade de responder às interações e aos estímulos do ambiente já nos primeiros minutos de vida (Cavalcanti, 2007).

Tanto Winnicott quanto Bowlby descrevem a interação que acontece entre o bebê e seus cuidadores principais, que geralmente são os pais, mas que também podem ser outros cuidadores, como as educadoras. As educadoras de berçário, especificamente, diferenciam-se das educadoras de crianças maiores pela intensidade de cuidados que os bebês exigem. Dar banho, trocar fraldas, alimentá-los, dar colo, oferecer suporte físico e emocional, protegendo-os dos perigos externos, são algumas das atividades diárias que, quando se trata de bebês, devem ser vistas e realizadas de forma lúdica, explicativa e, portanto, interativa (Guerra, 2010).

Por esse motivo, a rotina de trabalho das educadoras exige muito além de habilidades educacionais tradicionais, girando em torno, sobretudo, das necessidades emocionais dos bebês. Dessa forma, algumas profissionais, às vezes, consideram que não estão realizando a parte pedagógica e lúdica no berçário e, em alguns momentos, intitulam-se como "substitutas" da mãe. Neste estudo, porém, parte-se do pressuposto de que, do ponto de vista do bebê e de seu desenvolvimento, não faz sentido considerar determinadas interações como educativas ou pedagógicas e outras como interações de cuidado (Guollo, 2010). Todas essas interações, na verdade, buscam satisfazer múltiplas necessidades dos bebês e, de antemão, não possuem maior ou menor valor. Seu valor, na verdade, vai depender 
do quanto estão em consonância com as necessidades dos bebês em diferentes momentos da rotina.

Evidencia-se, a partir disso, o quanto as interações que as educadoras estabelecem com os bebês podem ser influenciadas por suas crenças em relação a diferentes aspectos, dentre eles o modo como os bebês se desenvolvem, suas necessidades e as práticas dos adultos consideradas mais adequadas para o bebê (Vartuli, 2005). Nesse sentido, estudos nacionais e internacionais, cujos resultados serão apresentados a seguir, investigaram as concepções de desenvolvimento e aprendizagem adotadas pelas educadoras, utilizando, em geral, a mesma classificação identificada por Daniels e Shumow (2003) ao realizarem uma revisão da literatura na área: concepção ambientalista, inatista e interacionista/construtivista.

Entre os estudos nacionais houve um predomínio da concepção ambientalista, a qual pressupõe que o desenvolvimento da criança é resultado da influência de fatores externos, ou seja, daquilo que vem de fora, do ambiente em que ela está inserida (Bahia, Magalhães, \& Pontes, 2011; Melchiori, Alves, Souza, \& Bugliani, 2007; Melchiori \& Biasoli-Alves, 2001). Assim, evidenciou-se que a criança tende a ser descrita como mais passiva frente ao seu desenvolvimento, que teria o adulto como principal protagonista. Por outro lado, o estudo de Brownlee, Berthelsen e Boulton-Lewis (2004), realizado na Austrália, evidenciou maior diversidade nas concepções das educadoras. Embora algumas tenham também enfatizado uma concepção mais ambientalista, focada nos processos de modelagem e repetição, outras evidenciaram uma concepção claramente construtivista, ancorada na autonomia da criança para fazer escolhas e resolver situações-problema e, assim, construir significados sobre o mundo.

É possível que a ênfase na concepção de desenvolvimento ambientalista esteja relacionada com o pouco conhecimento das educadoras sobre as principais necessidades físicas, emocionais e sociais dos bebês, bem como sobre suas competências e potencial de interação com o cuidador (Becker, Bernardi, \& Martins, 2013).
No estudo realizado por esses últimos autores, educadoras de berçário foram questionadas sobre as principais necessidades dos bebês, havendo um predomínio da necessidade de holding (ex. amor, carinho, atenção, aconchego). Outras necessidades foram pouco citadas, o que pode evidenciar um bebê visto como pouco ativo na exploração do ambiente e inclusive na interação com o adulto e outros bebês.

Resultado semelhante foi verificado por Berthelsen e Brownlee (2007) e Brownlee, Berthelsen e Segaran (2007), que, ao investigarem as crenças de educadoras e diretoras sobre o trabalho com crianças pequenas, verificaram grande ênfase nas funções afetivas da educadora, cujo objetivo seria suprir as necessidades do bebê de atenção individual e acolhimento emocional. Berthelsen e Brownlee (2007), em particular, discutiram que, de antemão, não se pode avaliar o quanto tal ênfase é mais ou menos adequada. No entanto, ressaltaram que se tais crenças derivam de compreensões intuitivas (e não teóricas) das educadoras sobre o que é bom para as crianças, é menos provável que a atuação seja de alta qualidade. Aliás, esse foi outro resultado verificado por esses autores, de que, em geral, apesar de enfatizar a função afetiva de sua atuação, as educadoras tenderam a mencionar com menor clareza e frequência os princípios fundamentais que orientam sua prática.

Por outro lado, tem-se sugerido também que outro aspecto que parece permear as concepções das educadoras sobre o desenvolvimento e aprendizagem seria uma necessidade de afirmação de espaço ou identidade. Nesse sentido, sentimentos de rivalidade por vezes verificados entre mães e educadoras podem ser fatores associados à supervalorização do protagonismo do adulto frente ao desenvolvimento da criança (Bahia et al., 2011; Melchiori et al., 2007; Melchiori \& Biasoli-Alves, 2001). Melchiori e Biasoli-Alves (2001), por exemplo, verificaram que educadoras consideraram a mãe como quem mais influenciava o desenvolvimento dos bebês, mas, na metade das vezes, a mãe era vista como exercendo influência negativa. Do mesmo modo, as mães participantes desse estudo também consideraram elas próprias quem mais influenciava 
o desenvolvimento dos filhos e, embora tenham mencionado que o ambiente da creche era importante, não deram grande ênfase ao papel das educadoras.

Nota-se, portanto, que as concepções das educadoras sobre o desenvolvimento infantil podem influenciar tanto sua relação com a mãe e a família, quanto sua relação com a criança. Quanto a esse último aspecto, alguns estudos demonstram que, em geral, as práticas de interação com a criança que são mais valorizadas pelas educadoras tendem a estar de acordo com sua concepção de desenvolvimento e aprendizagem (Bahia, 2008; Becker et al., 2013; Brownlee et al., 2004; McMullen et al., 2005; Ramos \& Salomão, 2013; Santos, 2012).

Nesse sentido, quando a concepção ambientalista predomina, verifica-se que as educadoras tendem a enfatizar práticas nas quais o adulto, direta e explicitamente, estimula o desenvolvimento ou treinamento de habilidades da criança. Por exemplo, no estudo de Becker et al. (2013), educadoras de berçário destacaram a importância da estimulação motora (ex. massagem, colocar de bruço) e da estimulação da linguagem (ex. conversar, nomear objetos, descrever a rotina). Já em outros estudos (Ramos \& Salomão, 2013; Santos, 2012), educadoras de crianças pré-escolares mencionaram mais as atividades dirigidas, os brinquedos educativos e as práticas de conversar e contar histórias.

Por sua vez, Berthelsen e Brownlee (2007) e Brownlee et al. (2004) verificaram que, as educadoras que possuíam uma concepção de desenvolvimento e aprendizagem construtivista, entendiam seu papel como parceiras na interação com a criança, no sentido de proporcionar e apoiar suas iniciativas e livre exploração, bem como utilizar perguntas-problema que suscitassem a construção de novos significados. Já Brownlee et al. (2007) constataram que os comentários das educadoras, ao relatarem o que consideravam um atendimento de qualidade para bebês e crianças pequenas, nada revelavam sobre como entendiam a natureza do desenvolvimento e da aprendizagem das crianças, o que poderia culminar em uma percepção difusa sobre seu papel na interação com as mesmas.
Considerando todos os aspectos até então expostos, este estudo teve como objetivo caracterizar as concepções de educadoras de berçário a respeito do desenvolvimento infantil e da interação educadora-bebê. Em particular, buscou-se descrever como as educadoras caracterizam o bebê e suas principais necessidades; identificar fatores que, para as educadoras, influenciam no processo de desenvolvimento do bebê; verificar como as educadoras percebem seu papel frente ao desenvolvimento do bebê e analisar o que as educadoras entendem por uma interação de qualidade entre educadora e bebê. Entende-se que um estudo dessa natureza é importante por aprofundar uma temática ainda pouco explorada no cenário nacional, especialmente no campo da educação de bebês. Conhecimentos mais sistemáticos a respeito das concepções das educadoras podem contribuir na elaboração de projetos de formação continuada que visem qualificar o atendimento prestado pelas escolas.

\section{Método}

\section{Participantes}

Participaram do estudo seis educadoras de um município da Serra Gaúcha, que atendiam crianças de berçário (crianças com idades entre quatro a dezesseis meses). As seis educadoras pertenciam a três diferentes escolas de Educação Infantil do município (duas de cada escola), sendo uma escola de cada região da cidade. A Tabela 1 apresenta as principais características sociodemográficas das educadoras. A idade das participantes variou entre 26 e 53 anos. Destaca-se ainda que três educadoras estavam cursando graduação em Pedagogia, embora possuíssem uma formação de magistério em nível médio. Por sua vez, uma educadora já havia concluído a graduação e duas tinham pós-graduação. Em geral, as educadoras já possuíam experiência como profissionais da Educação Infantil, uma vez que o tempo de atuação na área variou de 6 a 23 anos. No entanto, especificamente em relação à atuação no berçário, esse tempo foi menor, variando entre um e 8,5 anos. Todas as educadoras já haviam realizado capacitações específicas para o trabalho com bebês. 
Tabela 1

Caracterização Sociodemográfica das Educadoras Participantes

\begin{tabular}{|c|c|c|c|c|c|}
\hline $\begin{array}{l}\text { Identificação } \\
\quad \text { das } \\
\text { Educadoras }\end{array}$ & $\begin{array}{c}\text { Identificação } \\
\text { das } \\
\text { Instituições }\end{array}$ & $\begin{array}{l}\text { Idade } \\
\text { (anos) }\end{array}$ & Escolaridade & $\begin{array}{c}\text { Tempo de atuação } \\
\text { na Educação Infantil } \\
\text { (anos) }\end{array}$ & $\begin{array}{c}\text { Tempo de atuação } \\
\text { no Berçário } \\
\text { (anos) }\end{array}$ \\
\hline E1 & I1 & 53 & $\begin{array}{c}\text { Superior } \\
\text { (Pedagogia) }\end{array}$ & 23 & 1 \\
\hline E2 & I1 & 40 & $\begin{array}{l}\text { Pós-graduação } \\
\text { (Psicopedagogia) }\end{array}$ & 21 & 2 \\
\hline E3 & I2 & 31 & $\begin{array}{l}\text { Superior incompleto } \\
\text { (Pedagogia) }\end{array}$ & 12 & 2 \\
\hline E4 & I2 & 44 & $\begin{array}{l}\text { Superior incompleto } \\
\text { (Pedagogia) }\end{array}$ & 18,5 & 8,5 \\
\hline E5 & $\mathrm{I} 3$ & 28 & $\begin{array}{c}\text { Pós-graduação } \\
\text { (Educação Profissional) }\end{array}$ & 6 & 2 \\
\hline E6 & I3 & 26 & $\begin{array}{l}\text { Superior incompleto } \\
\text { (Pedagogia) }\end{array}$ & 9 & 2 \\
\hline
\end{tabular}

\section{Instrumentos}

Questionário Sociodemográfico: utilizado para investigação de dados pessoais e profissionais das educadoras que participaram da pesquisa (por exemplo, idade, formação e tempo de atuação na Educação Infantil).

Entrevista de Concepções de Educadoras sobre Desenvolvimento Infantil e Interação Educadora-Bebê: refere-se a uma entrevista semiestruturada, elaborada para o presente estudo, a qual teve por objetivo investigar as concepções das educadoras em relação a dois aspectos: (a) processo de desenvolvimento do bebê (por exemplo, Como você descreveria um bebê? De forma simples e utilizando suas próprias palavras, você poderia me explicar como ocorre o desenvolvimento do bebê?); e (b) interação educadora-bebê e papel da educadora no desenvolvimento do bebê (por exemplo, Quais são seus principais objetivos como uma educadora de bebês? Como você descreveria uma interação de qualidade entre educadora e bebê?). Cada um desses aspectos foi investigado através de um bloco de questões abertas. Entende-se que o formato e o conteúdo das questões dessa entrevista permitiram explorar as concepções das educadoras de uma perspectiva mais explícita e conceitual, quando comparada à entrevista que será apresentada a seguir.

Entrevista sobre as Crenças de Educadoras de Berçário (Martins \& Gabriel, 2013): refere-se a uma entrevista semiestruturada, que tem como objetivo investigar as crenças das educadoras em relação a situações de interação diárias entre educadoras e bebês. Para tanto, a entrevista apoia-se em descrições de seis situações comumente vividas no dia a dia das educadoras com os bebês e solicita que as respondentes avaliem cada uma dessas situações (por exemplo),

$O$ bebê, de aproximadamente 10 meses, estava chorando baixo [resmungando] no berço e a educadora se aproximou dele, pegou-o no colo e falou com o bebê. O bebê acalmou-se e foi conduzido, ainda no colo, para o trocador. $O$ bebê estava usando fralda e uma blusa. A educadora deitou o bebê e retirou sua fralda. O bebê virou-se de bruços enquanto a educadora pegava a fralda limpa. Logo em seguida, a educadora trocou a fralda do bebê com ele ainda de bruços. O que tu pensas sobre a forma de agir da educadora? Por que tu achas que a educadora agiu dessa forma? Em que momentos tu avalias que a educadora agiu de 
forma adequada? Por quê? O que tu avalias que a educadora poderia ter feito diferente? Por quê?.

Nesse sentido, entende-se que o formato e o conteúdo das questões permitem explorar as concepções das educadoras de uma perspectiva mais implícita e vivencial. Para verificar a adequação das questões dessa entrevista para fins do presente estudo, foi realizada uma aplicação piloto com uma educadora que atua em uma escola do município em questão. Essa aplicação demonstrou que as situações descritas na entrevista foram de fácil entendimento das educadoras e que poderiam ser utilizadas para apreender os fenômenos de interesse do presente estudo.

\section{Procedimentos de Coleta e Análise dos Dados}

Inicialmente, contatou-se a Secretaria $\mathrm{Mu}$ nicipal de Educação e Cultura (SEMEC) do município, visando obter a autorização formal para a realização do estudo junto às educadoras. Nessa ocasião, foram selecionadas as escolas participantes, buscando escolas que representassem diferentes regiões da cidade. Em seguida, as instituições foram contatadas via telefone e por ofício, de modo a esclarecer os objetivos e procedimentos da pesquisa, bem como agendar uma visita a cada escola. Na visita, realizou-se o convite pessoalmente para as educadoras e agendou-se o dia e o horário que mais convinha à participante.

A coleta de dados se deu, portanto, de forma individual, e iniciou com a assinatura do Termo de Consentimento Livre e Esclarecido (TCLE). Em seguida, foi realizada a aplicação dos instrumentos, todos no formato de entrevista. Primeiramente, aplicou-se o Questionário Sociodemográfico, seguido da Entrevista sobre as crenças de educadoras de berçário e, por fim, as educadoras responderam a Entrevista de concepções de educadoras sobre desenvolvimento infantil e interação educadora-bebê. A aplicação de todos os instrumentos foi gravada e, posteriormente, transcrita.

A análise e interpretação dos dados foi realizada qualitativamente. Para tanto, recorreu-se a uma análise de conteúdo (Bardin, 1977), considerando categorias previamente definidas, bem como subcategorias elaboradas a partir dos próprios dados (Laville \& Dione, 1999). Os seguintes procedimentos foram adotados para a realização da análise: (a) inicialmente, a primeira autora, a partir da leitura do material, derivou subcategorias que descreviam as concepções das educadoras em cada categoria anteriormente definida; (b) após, a segunda autora também realizou a leitura do material e verificou a adequação das classificações realizadas pela primeira autora, sugerindo eventuais modificações, que foram discutidas, buscando um consenso; (c) finalmente, foi explorado qualitativamente o conteúdo das respostas em cada categoria e subcategoria, visando à apreensão de seu significado e suas nuances.

Com base nos objetivos da pesquisa e nos instrumentos propostos, as seguintes categorias nortearam a análise:

1. Concepções sobre o bebê e suas principais necessidades: como as educadoras definem os bebês e o que elas julgam ser importante para eles se desenvolverem;

2. Concepções sobre o processo de desenvolvimento do bebê: como as educadoras entendem que ocorre o desenvolvimento do bebê;

3. Concepções sobre o papel do educadora no desenvolvimento do bebê: como as educadoras se veem diante do processo de desenvolvimento do bebê; e

4. Concepções sobre a interação educadora-bebê: como as educadoras concebem uma interação de qualidade entre educadora e bebê.

As respostas dadas aos dois instrumentos utilizados para coleta de dados foram utilizadas para elaborar as categorias e subcategorias de análise. Nesse sentido, não foram feitas qualquer distinção entre os dois instrumentos no momento da análise.

\section{Considerações Éticas}

O projeto foi avaliado e aprovado pelo Comitê de Ética em Pesquisa das Faculdades Integradas de Taquara - FACCAT (Protocolo $\mathrm{n}^{\circ}$ 675). 


\section{Resultados}

Os resultados serão apresentados conforme cada categoria que norteou a análise dos dados. Para cada uma delas, serão fornecidas informações qualitativas, ilustradas por vinhetas, bem como a frequência de educadoras que mencionaram respostas em cada subcategoria.

\section{Categoria I: Concepções sobre o Bebê e suas Principais Necessidades}

Duas subcategorias foram elaboradas para descrever as concepções das educadoras nesta categoria: "Concepções sobre o bebê" e "Concepções sobre as principais necessidades do bebê". No que diz respeito às "Concepções sobre o bebê", três educadoras o descreveram como "Um ser em desenvolvimento". Nesse sentido, para essas educadoras, os bebês são vistos como seres em constante formação: "Para mim o bebê é um serzinho em formação. Um ser que em todos os segundos está em formação, qualquer manifestação que ele tenha faz parte da formação dele" (E2)3; "Eu vejo como um serzinho em desenvolvimento, eles estão em constante desenvolvimento. Todos os dias eles estão em constante evolução" (E4). Por outro lado, quatro educadoras descreveram o bebê como "Um ser a ser lapidado", o que indica que, para elas, seu desenvolvimento depende, em grande parte, de um adulto para moldá-lo e ensiná-lo: "Até comento com os pais que é uma pedra bruta e que nós vamos lapidá-la" (E1);

Eles são seres que estamos preparando e se a gente deixar eles fazerem tudo que quiserem, eles fazem. Por isso a gente começa desde cedo. Não puxa, não bate, o colega não gosta disso, eles entendem e aprendem a fazer certo. (E1)

Ainda, três educadoras relataram que entendem o bebê como "Ativo e curioso": "Acho que um ser em desenvolvimento mesmo, lembro de seres bem ativos, bem curiosos" (E5). Finalmente, três educadoras descreveram o bebê como "Esperto": "Eles são muito espertos" (E1).

\footnotetext{
A autoria das vinhetas será identificada pela letra "E", seguida do número de identificação de cada educadora.
}

A segunda subcategoria analisada foi "Concepções sobre as principais necessidades do bebê". Quatro das seis educadoras entrevistadas falaram sobre a importância dos "Cuidados afetivos": "Carinho de pais, carinho de família, de professores" (E1); enquanto três mencionaram os "Cuidados físicos": " $E$ importante a higiene, a alimentação, o cuidado" (E2). Nenhuma outra necessidade do bebê foi mencionada pelas educadoras.

\section{Categoria II: Concepções sobre o Processo de Desenvolvimento do Bebê}

Para esta segunda categoria, duas subcategorias foram criadas: "Como o desenvolvimento ocorre" e "O que influencia no desenvolvimento saudável". Para duas educadoras, o desenvolvimento do bebê ocorreria "Por fases": "Eles vão por fases, por passos" (E1); "Desde que ele começa sendo uma criança totalmente dependente até eles fazerem por eles mesmos" (E6). Além disso, quatro educadoras afirmaram que é "Por estimulação" que os bebês vão passando de uma fase para a outra: "É um processo contínuo e que precisa necessariamente de estímulos" (E5).

A "Estimulação" apareceu também na fala de três educadoras quando investigadas sobre suas concepções em relação à subcategoria " $\mathrm{O}$ que influencia no desenvolvimento saudável": "E eles precisam de estímulo toda hora, em tudo que eles vão fazer, cada parte da rotina deles é importante a gente estimular, sabe?" (E5); o que indica que as educadoras de berçário veem na estimulação um fator de extrema importância para o desenvolvimento do bebê. Por outro lado, "Ter um ambiente seguro, tranquilo e afetivo" foi também uma subcategoria identificada a partir das respostas de quatro das seis educadoras: "Precisam de um ambiente tranquilo, seguro" (E6); "O ambiente tem que ser acolhedor" (E4). Uma das educadoras também citou em três momentos da entrevista que considera importante ter um "Ambiente físico adequado": "Uma sala maior, com mais prateleiras, com um fraldário, com mais berços, porque hoje eles não têm bercinhos. O espelho, tatame, brinquedos" (E5); “O espaço fisico influencia, tem que ser adequado para a idade, tem que ter brinquedos, tem que 
ter figuras, colorido, mas também não pode ser muito poluido" (E5).

Ainda no que diz respeito à subcategoria " $\mathrm{O}$ que influencia no desenvolvimento saudável”, três educadoras afirmaram acreditar que os bebês necessitam de "Cuidado de pessoas tranquilas e que gostem de bebês": "Precisam que as pessoas que cuidam deles sejam comprometidas com o que fazem. Que é diferente de formação, as pessoas precisam ter paciência, empatia, gostar do que fazem" (E5); "Tem que ser pessoas carinhosas, tem que ser pessoas educadas e que gostem de bebês" (E6). Nesse sentido, por detrás dessas concepções, parece haver uma crença de que algumas pessoas teriam o dom para cuidar de bebês. Finalmente, o trabalho de "Parceria entre pais e professores" é uma concepção presente nessa mesma subcategoria, lembrado por três educadoras em suas respostas: "Tudo colabora, a participação de pais e da escola. Porque onde não tem ajuda de uma das partes não dá, o desenvolvimento atrasa" (E1).

\section{Categoria III: Concepções sobre - Papel da Educadora no Desenvolvimento do Bebê}

$\mathrm{Na}$ terceira categoria, duas subcategorias foram elaboradas: "Objetivos como educadora de berçário" e "Características de uma educadora de berçário". Quanto à primeira, três educadoras relataram que um dos seus objetivos é "Motivar e ensinar": "Incentivá-los a fazer o que a gente quer. Que é da idade deles né. E sempre através do lúdico" (E3); "Ajudá-los a descobrir as coisas, ensinar a comer, a sentar, a caminhar, falar, etc" (E4); "Conversar com o outro bebê, ensinar o outro a fazer carinho, aprender a respeitar" (E6). De forma mais específica, para quatro educadoras, seu objetivo enquanto profissionais da área seria "Auxiliar no desenvolvimento dos bebês": "Sempre colaborar para qualquer desenvolvimento" (E2); “. . . ajuda-los no desenvolvimento, espero que tudo que eles não conseguiam fazer e que é da idade deles ao sair da minha turminha eles já estejam fazendo, já estejam mais desenvolvidos" (E5).

Todas as seis entrevistadas descreveram características que uma profissional deve possuir para trabalhar no berçário. "Gostar do que faz/ ser paciente" foi uma característica citada pelas seis educadoras: "Primeiro tem que amar o que faz. Buscar ideias novas para motiva-los, buscar músicas, canções. Adapta-los em uma rotina" (E3); "Não pode ser aquelas pessoas gritonas, pessoas que fazem as coisas no automático" (E6); "Profes não podem se importar com o choro, ficar irritadas, eles choram mesmo e a gente tem que ter paciência" (E5). Além disso, em duas das entrevistas surgiu a ideia de que as educadoras devem "Ser sensíveis ao que eles necessitam":

. . . ser sensivel, estar sensivel aos sinais dos bebês, como os bebês não falam, a gente tem que estar sensivel aos sinais que eles nos passam, é através dos sinais que eles vão nos dizer o que precisam. (E5)

Estimular sempre o desenvolvimento e a aprendizagem de acordo com as necessidades deles, as realidades, as necessidades escolares e sempre ir adequando com aquilo que a gente tem para a faixa etária deles. Porque às vezes a gente quer uma coisa e não se dá conta de que o aluno não quer aquilo, que não é aquilo que ele necessita. A professora tem que sempre tentar manter esse olhar para as necessidades do aluno. (E4)

\section{Categoria: Concepções sobre a Interação Educadora-Bebê}

A última categoria analisada focalizou as concepções das educadoras sobre a interação educadora-bebê, sendo organizado em duas subcategorias "Postura profissional esperada" e "Elementos de uma interação educadora-bebê de qualidade". Referente à primeira, as respostas das educadoras relacionaram-se a fundamentos básicos que devem guiar a interação com o bebê. Seis educadoras relataram que é importante "Priorizar os bebês" em relação a outras atividades presentes em sua rotina na escola: "Quando a gente tem mais experiência, a gente sabe que os bebês são os mais importantes e que vai dar tempo de fazer o resto e, se não der, paciência, o resto que espere" (E6); "Só que em primeiro lugar são os bebês, depois as agendas. Até porque 
se uma está trocando a outra tem que interagir com os alunos" (E4). Ainda no que diz respeito à subcategoria "Postura profissional esperada", cinco educadoras relataram que procuram "Ser uma fonte de confiança e segurança" para os bebês: "Sabem que vão ganhar comida, então eles têm confiança no lugar, têm confiança em nós e quando estão com fome já conseguem esperar um pouquinho" (E1);

É que não é fácil tu tirar um bebê do colo da mãe, porque geralmente eles não querem sair. Mas quando eles confiam nas profes, eles chegam e se jogam. Acho que isso é por causa do vínculo que a gente cria e eu julgo que isso é uma interação de qualidade. (E5) Também, duas educadoras enfatizaram que se deve "Ter respeito pelo ritmo e particularidades do bebê": "Respeitar as qualidades e dificuldades de cada um" (E2); "Como uma interação de respeito, tanto da nossa parte quanto da deles" (E1).

Em relação à segunda subcategoria deste eixo, denominada "Elementos de uma interação educadora-bebê de qualidade", cinco educadoras mencionaram "Aproveitar as atividades da rotina para interagir e estimular". Assim, evidenciaram a ideia de que no berçário tudo é pedagógico, no sentido de que os bebês aprendem em todos os momentos, inclusive no acolhimento, troca de fralda e alimentação, momentos considerados de grande interação: "Quando chega a hora de fazer a troca é uma hora de interação, uma hora de integração entre a profe e a criança, a criança tem que estar te olhando, não de qualquer jeito tu botar a criança" (E1); "Na hora do almoço tem que ter sim a interação, mas tem que ter o limite, tem que saber que agora é a hora da alimentação e é igual para todos" (E2); "Eles descobrem que eles conseguem caminhar, eles descobrem que eles começam a falar, então é aproveitar todos esses momentos deles" (E4).

Porém, para a educadora estar atenta a esses momentos da rotina e percebê-los como momentos de interação, três educadoras relataram que devem "Ser afetiva/dedicada":

Quando tu vai trocar uma fraldinha por exemplo, não é uma coisa mecânica, pã, pã, pã e trocou! Não, ali naquele momento tu pode expressar um lado afetivo com ele, tu pode fazer uma "coceguinha" no pé, na barriga. Tu pode estimular, o bracinho e a perninha, né? (E4)

"Eles não são, não fazem parte da mobília da sala [risos], eles estão ali porque precisam do carinho, precisam do toque, do afeto e eles estão longe da família, então temos que entender esse lado deles também" (E4).

Duas educadoras disseram que o adequado seria "Deixar os bebês explorarem o próprio corpo". Ao avaliarem a ação de uma educadora hipotética, através da entrevista, afirmaram: "Mas ela poderia ter deixado ele explorar o corpo" (E4); e a outra disse: "Ela não está totalmente errada, porém ela deveria deixar porque ele estava descobrindo a mãozinha" (E3). Finalmente, em contrapartida a essa concepção de que elas que devem deixar os bebês mais livres, duas educadoras citaram que devem "Explicar/demonstrar como os bebês devem interagir": "Ela deveria explicar para o outro que isso era errado, que o colega não queria, sempre conversando com eles, porque se a gente não explicar eles vão aprender como?" (E5); "Porque ela deveria explicar como ele deve agir com os colegas, deve explicar que estava errado" (E3).

\section{Discussão e Considerações Finais}

Este estudo partiu do pressuposto de que para melhor compreender as interações entre educadoras e bebês no berçário faz-se relevante acessar as concepções que as embasam e dão significado. Logo ao nascer e, talvez, antes mesmo do nascimento, os adultos apresentam tais concepções para os bebês, seja na interação direta com eles, seja na forma com que organizam o ambiente a sua volta (Carvalho et al., 2012). Dessa forma, entende-se que as concepções que os adultos possuem vão orientá-los quanto a sua forma de agir e interagir com os bebês. Considerando esses aspectos, o presente estudo buscou caracterizar as concepções das educadoras de berçário em relação ao desenvolvimento infantil e a interação educadora-bebê.

No que diz respeito ao desenvolvimento infantil, o estudo investigou tanto as concepções 
das educadoras sobre a natureza e necessidades do bebê, quanto sobre a forma com que se desenvolvem. Os resultados indicaram que, em geral, as educadoras entendem o bebê como um ser em formação, em desenvolvimento, que por vezes foi descrito como um ser ativo, curioso e esperto. No entanto, chamou atenção que a maioria das educadoras também explicitou a ideia de que o bebê precisa ser "lapidado" para ajustar-se ao mundo, ou seja, precisa de um adulto para orientar seu desenvolvimento, especialmente através dos limites (dizer "não"). Nesse sentido, algumas ressaltaram que os bebês, inicialmente, não sabem bem o certo ou errado, não sabem distinguir o que gostam ou não gostam, e, assim, elas irão auxiliá-los nessa descoberta.

Verificou-se, portanto, que, desde as primeiras falas das educadoras, o bebê pareceu ser descrito como mais passivo e pouco competente frente ao seu processo de desenvolvimento. Outro resultado que reforçou essa ideia foram as concepções das educadoras sobre as principais necessidades do bebê, que, de forma surpreendente, tiveram como foco somente a necessidade de cuidados afetivos (basicamente o carinho) e físicos (alimentação e higiene), resultado semelhante ao verificado por Becker et al. (2013), Berthelsen e Brownlee (2007) e Brownlee et al. (2007), os quais também investigaram crenças de educadoras de berçário.

Não se pode negar que as necessidades mencionadas pelas educadoras são fundamentais para a sobrevivência e desenvolvimento do bebê. No entanto, ressalta-se que um bebê visto como ativo e competente possui necessidades que vão além desses aspectos, como por exemplo, a de interagir com o mundo físico e social à sua volta, incluindo trocas e compartilhamento de emoções com outros bebês e adultos de referência (Carvalho et al., 2012). Também uma necessidade bastante central para os bebês é a de conhecer e testar as potencialidades de seu corpo, através de movimentos livres em diferentes posições (Pikler, 1998).

Dessa forma, é possível afirmar que, em geral, as concepções das educadoras participantes deste estudo se aproximaram da concepção ambientalista de desenvolvimento, assim como já verificado em outros estudos (Bahia et al., 2011; Melchiori et al., 2007; Melchiori \& Biasoli-Alves, 2001). Indícios dessa concepção também foram encontrados nos resultados referentes ao eixo temático "Concepções sobre o processo de desenvolvimento do bebê". Neste eixo, o aspecto mais enfatizado pelas educadoras foi o papel da estimulação, citada como mecanismo que explica como o desenvolvimento ocorre e o promove de forma saudável. Nesse sentido, a estimulação foi vista como o motor principal do desenvolvimento, que contribui para que o bebê evolua de uma fase a outra.

Chama atenção o quanto a concepção ambientalista de desenvolvimento ainda predomina entre as educadoras, apesar da grande disseminação e aceitação de abordagens interacionistas no campo da educação. Talvez, a grande ênfase no conceito de estimulação pode estar revelando interpretações equivocadas dessas últimas abordagens, que apesar de enfatizarem o papel do adulto na interação com a criança, o fazem considerando-o um mediador que acompanha e constrói junto com ela seu conhecimento sobre o mundo e sobre si mesmo (Carvalho et al., 2012; Felipe, 2001). O adulto, dessa forma, não impõe à criança algo que vem de fora e, portanto, a mesma não é vista como passiva frente a esse processo.

Além da estimulação, por outro lado, algumas educadoras, assim como no estudo de Lordelo et al. (2007), mencionaram que um ambiente adequado, espaçoso e tranquilo também contribui para a promoção de um desenvolvimento saudável, já que auxilia a criança a estabelecer bons vínculos e interações sadias. Nesse sentido, pode-se pensar que a própria organização do ambiente seria uma forma de estimulação ao desenvolvimento do bebê, no sentido de que o direciona para algumas possibilidades, mas sem impedir o protagonismo do bebê nesse processo. No entanto, não foi possível verificar se as educadoras entendem a organização do ambiente também como uma forma de estimulação. $\mathrm{Na}$ verdade, acredita-se que, quando as educadoras falaram em estimulação, pareceram referir-se mais a práticas dos adultos que diretamente teriam algum resultado sobre o desenvolvimento 
do bebê, como por exemplo, chamar atenção para objetos, treinar o caminhar, o sentar, entre outros. Já quando mencionaram outros fatores de influência sobre o desenvolvimento (ex. ambiente), talvez, tenham considerado seu efeito mais indireto.

Por exemplo, outro fator mencionado pelas educadoras que influenciaria o desenvolvimento do bebê de forma mais indireta é receber o cuidado de pessoas tranquilas e que gostam do que fazem. Essa concepção parece estar embasada na crença de que algumas pessoas seriam predispostas para trabalhar com bebês, por serem calmas e gostarem de estar com eles, enquanto outras não poderiam assumir o papel de educadoras de berçário. Por um lado, tal concepção revela que, em alguma medida, as educadoras reconhecem a importância das primeiras relações na vida do bebê, assim como enfatizado por Bowlby (1969/2002) e Winnicott (1971). Talvez, por isso, elas acreditem que o cuidado recebido nesta fase precisa ser especial e feito por alguém emocionalmente disponível.

Por outro lado, porém, não se pode deixar de destacar que a ideia de que somente pessoas que gostam de bebês deveriam trabalhar no berçário torna essa profissão mais intuitiva e vivencial do que técnica e baseada em conhecimentos. Acredita-se, porém, que esses dois aspectos devem caminhar juntos na formação dos educadores de bebês, especialmente porque sua combinação permite delinear uma identidade profissional específica, que supera a ideia de "mãe substituta" e pode atenuar eventual rivalidade presente na relação entre mães e educadoras (Bahia et al., 2011; Melchiori et al., 2007; Melchiori \& Biasoli-Alves, 2001).

Indícios a respeito de alguns conhecimentos teórico-técnicos que parecem guiar o fazer das educadoras foram verificados quando se questionou sobre suas concepções em relação à postura profissional esperada. Por exemplo, todas elas relataram que o mais importante é priorizar o bebê no cotidiano do trabalho. Isso significa que reconhecem a importância de dar suporte primeiro a ele e depois realizar outras atividades exigidas pela sua função. Ao encontro disso, segundo elas, as educadoras devem ser uma fon- te de segurança e confiança para os bebês, para que eles as tenham como referência de apoio, tal qual foi verificados nos estudos de Berthelsen e Brownlee (2007) e Brownlee et al. (2007). Duas educadoras ainda complementaram com o entendimento de que precisam respeitar o ritmo e individualidade dos bebês, o que denota um respeito pelas características do bebê em geral e de cada indivíduo especificamente. Esse é um atributo importante das relações entre adultos e bebês, que, segundo Bowlby (1969/2002) contribui para a construção de um apego seguro.

Ainda no que diz respeito à interação educadora-bebê, foi possível perceber o quanto os relatos das educadoras foram ao encontro das ideias de outros autores (Becker et al., 2013), especialmente quando afirmaram que, para se ter uma interação de qualidade, deve-se aproveitar todos os momentos da rotina dos bebês, incluindo momentos de cuidado e momentos de exploração. Guollo (2010), nesse sentido, afirma que no berçário qualquer atividade deve ser realizada através de uma interação de qualidade, sendo isso que lhe garantirá maior ou menor valor pedagógico e não o tipo de atividade propriamente dita.

Para as educadoras entrevistadas, uma interação de qualidade requer que as profissionais do berçário sejam afetivas e dedicadas, sempre demonstrando carinho nas atividades de rotina. Não se pode esquecer, no entanto, que o principal indicador de qualidade da interação adulto-bebê, para autores como Bowlby (1969/2002) e Winnicott (1971), diz respeito à sensibilidade do adulto. Ou seja, além de ser afetivo, o adulto deve responder de forma rápida e adequada aos sinais que o bebê emite. Essa característica, porém, não foi mencionada de forma explícita pelas educadoras participantes do presente estudo.

Da mesma forma, embora Bowlby (1969/2002) e Winnicott (1971) entendam a interação como um fenômeno bidirecional, que acontece entre dois sujeitos ativos, em apenas dois momentos das entrevistas foi mencionado que uma interação de qualidade também envolve deixar que os bebês descubram-se e ser sensível quanto aos desejos e expressões de autonomia do bebê. Ao contrário disso, enfatizou-se mais 
a questão de que é a educadora que deve dar o exemplo de como interagir, que deve explicar para os bebês o que eles devem fazer e como devem fazer, priorizando-se, assim, o polo do adulto. Esse resultado vai ao encontro de estudos que verificaram que as práticas de interação mais valorizadas por educadoras infantis tendiam a enfatizar o papel ativo do adulto como agente que apresenta estímulos externos à criança (Becker et al., 2013; Ramos \& Salomão, 2013; Santos, 2012).

Apesar de os resultados verificados nesse estudo serem instigantes, ressalta-se que todos eles derivaram da análise das entrevistas realizadas com as educadoras, que possibilitam descrever suas concepções, mas não necessariamente o que acontece no seu dia a dia na escola. Portanto, sugere-se que novos estudos possam confrontar as concepções dessas profissionais com sua forma de interagir com os bebês no berçário. Além disso, sugere-se também que outros estudos explorem eventuais influências de aspectos contextuais (ex. proposta pedagógica e valores de cada escola) e da escolaridade das educadoras em suas concepções, o que não foi discutido no presente estudo.

De maneira geral, o estudo apontou que as educadoras entrevistadas têm como concepção o entendimento de que os bebês são prioridade em seu trabalho, demonstrando, dessa forma, muita dedicação para com eles. Por outro lado, verificou-se que, possivelmente, ainda fazem uma leitura equivocada dos autores interacionistas, entendendo o bebê como alguém mais passivo frente ao seu processo de desenvolvimento, bem como na interação com o adulto. Nesse sentido, ressalta-se a extrema importância da formação continuada, como estratégia para construir novas compreensões sobre o bebê e ampliar o escopo de ações da educadora de berçário para além das já consolidadas.

\section{Referências}

Bahia, C. D. C. S. (2008). O pensar e o fazer na creche: Um estudo a partir de crenças de mães $e$ professoras (Tese de doutorado, Universidade Federal do Pará, Belém, PA, Brasil).
Bahia, C. D. C. S., Magalhães, C. M. C., \& Pontes, F. A. R. (2011). Crenças de mães e professoras sobre o desenvolvimento da criança. Fractal: Revista de Psicologia, 23(1), 99-122. Recuperado em http://repositorio.ufpa.br/jspui/handle/2011/2523

Bardin, L. (1977). Análise de conteúdo. Lisboa: Edições 70.

Becker, S. M. S, Bernardi, D., \& Martins, G. D. F. (2013). Práticas e crenças de educadoras de berçário sobre cuidado. Psicologia em Estudo, 18(3), 551-560. doi:10.1590/S141373722013000300016

Berthelsen, D., \& Brownlee, J. (2007). Working with toddlers in child care: Practitioners' beliefs about their role. Early Childhood Research Quarterly, 22(3), 347-362.

Bowlby, J. (2002) Apego e perda. São Paulo, SP: Martins Fontes. (Original publicada em 1969)

Brownlee, J., Berthelsen, D., \& Boulton-Lewis, G. (2004). Working with toddlers in child care: personal epistemologies and practice. European Early Childhood Education Research Journal, 12(1), 55-70.

Brownlee, J., Berthelsen, D., \& Segaran, N. (2007). Childcare workers' and centre directors' beliefs about infant childcare quality and professional training. Early Child Development and Care, 179(4), 453-475.

Carvalho, A. M. A., Pedrosa, M. I., \& Rossetti-Ferreira, M. C. (2012). Aprendendo com a criança de zero a seis anos. São Paulo, SP: Cortez.

Cavalcanti, S. F. L. (2007). A importância das primeiras vivencias para o desenvolvimento psicomotor [Monografia]. Rio de Janeiro, RJ: Universidade Candido Mendes.

Daniels, D. H., \& Shumow, L. (2003). Child development and classroom teaching: A review of the literature and implications for educating teachers. Journal of Applied Developmental Psychology, 23(5), 495-526.

Felipe, J. (2001). O desenvolvimento infantil na perspectiva sociointeracionista: Piaget, Vygotsky, Wallon. In C. M Craidy \& G. E. P. S. Kaercher (Eds.), Educação Infantil: Pra que te quero? (pp. 27-37). Porto Alegre, RS: Artmed.

Guerra, V. (2010). La violencia del cuidado del bebe y el placer da la subjetivación em el jardin de infantes. Trabalho apresentado na Jornada de 
Educación Inicial y Psicoanálisis "Crecer com Outros”. Montevideo: Asociación Psicoanalítica del Uruguay.

Guollo, R. P. (2010). Percepções das educadoras no berçário: Entre o cuidar e o educar [Monografia]. Criciúma, SC: Universidade do Extremo Sul Catarinense.

Harkness, S., \& Super, C. M. (1996). Introduction. In S. Harkness \& C. M. Super, Parent's cultural belief systems: Their origins, expressions, and consequences (pp. 1-23). New York: The Guilford Press.

Instituto Nacional de Estudos e Pesquisas Educacionais Anísio Teixeira. (2013). Resultados finais do Censo Escolar (redes estaduais e municipais). Recuperado em http://portal.inep.gov.br/ basica-censo

Instituto Nacional de Estudos e Pesquisas Educacionais Anísio Teixeira. (2015). Resultados finais do Censo Escolar (redes estaduais e municipais). Recuperado em http://portal.inep.gov.br/ basica-censo

Laville, C., \& Dionne, J. (1999). A construção do saber: Manual de metodologia da pesquisa em ciências humanas. Porto Alegre, RS: Artmed.

Lordelo, E. R., Chalhub, A. A., Guirra, R. C., \& Carvalho, C. S. (2007). Contexto e desenvolvimento cognitivo: Freqüência à creche e evolução do desenvolvimento mental. Psicologia: Reflexão e Crítica, 20(2), 324-334. doi:10.1590/S010279722007000200019

Martins, G. D. F., \& Gabriel, M. R. (2013). Entrevista sobre as crenças de educadoras de berçário. Manuscrito não publicado. Porto Alegre, RS.

McMullen, M., Elicker, J., Wang, J., Erdiller, Z., Lee, S. M., Lin, C. H., \& Sun, P. Y. (2005). Comparing beliefs about appropriate practice among early childhood education and care professionals from the US, China, Taiwan, Korea and Turkey. Early Childhood Research Quarterly, 20(4), 451-464

Melchiori, L. E., Alves, Z. M. M. B., Souza, D. C., \& Bugliani, M. A. P. (2007). Família e creche: Crenças a respeito de temperamento e desempenho de bebês. Psicologia: Teoria $e$ Pesquisa, 23(3), 245-252. doi:10.1590/S010237722007000300002
Melchiori, L. E., \& Biasoli-Alves, Z. M. M. (2001). Crenças de educadoras de creche sobre temperamento e desenvolvimento de bebês. Psicologia: Teoria e Pesquisa, 17(3), 285-292. doi:10.1590/ S0102-37722001000300011

Ministério da Educação. (2014). Planejando a próxima década: Conhecendo as 20 metas do Plano Nacional de Educação. Recuperado em http:// pne.mec.gov.br/images/pdf/pne_conhecendo_20_metas.pdf

Piaget, J. (1978). O nascimento da inteligência da criança (3. ed.). Rio de Janeiro, RJ: Zahar. (Original publicada em 1936)

Pikler, E. (1998). Importancia del movimiento en el desarrollo de la persona. Revista La Hamaca, 9.

Ramos, D. D., \& Salomão, N. M. R. (2013). Desenvolvimento infantil: Concepções e práticas de educadoras em creches públicas. Psicologia: Teoria e Prática, 15(3), 200-213. Recuperado em http://pepsic.bvsalud.org/scielo.php?script=sci arttext\&pid=S1516-36872013000300015

Santos, E. R. F. (2012). Concepções de desenvolvimento infantil e estilos comunicativos nas interações educador-criança (Tese de doutorado, Universidade Federal da Paraíba, João Pessoa, PB, Brasil).

Vartuli, S. (2005). Beliefs: The heart of teaching. Young Children, 60(5), 76-86.

Vygotsky, L. S. (1984). A formação social da mente. São Paulo, SP: Martins Fontes.

Wallon, H. (1995). A evolução psicológica da criança. Lisboa: Edições 70. (Original publicada em 1941)

Winnicott, D. W. (1971). O papel do espelho da mãe e da família no desenvolvimento infantil. In $O$ brincar e a realidade (pp. 153-162). Rio de Janeiro, RJ: Imago.

Winnicott, D. W. (1985). A criança e seu mundo (Á. Cabral, Trad.). Rio de Janeiro, RJ: Zahar. (Original publicada em 1964)

Recebido: 20/08/2015

$1^{a}$ revisão: 22/01/2016

Aceite final: 25/01/2016 